\title{
Assessment of Off-Site Consequences Due to Severe Nuclear Accident According to Release Pathway Reduction Mechanisms Using Computer Code
}

\author{
Elsayeda Farid Salem ${ }^{1}$, Asmaa. Khalill Abdeen ${ }^{2}$, Mohamed Abdelrahman Salama ${ }^{2}$ \\ ${ }^{1}$ Nuclear Law and Nuclear Licenses Department, Egyptian Nuclear and Radiological Regulatory Authority, Cairo, Egypt \\ ${ }^{2}$ Quality Assurance Department, Egyptian Nuclear and Radiological Regulatory Authority, Cairo, Egypt
}

Email address:

sayeda_f@yahoo.com (E. F. Salem), asmaak@hotmail.com (Asmaa. K. Abdeen), m_salama@hotmail.com (M. A. Salama)

\section{To cite this article:}

Elsayeda Farid Salem, Asmaa. Khalill Abdeen, Mohamed Abdelrahman Salama. Assessment of Off-Site Consequences Due to Severe Nuclear Accident According to Release Pathway Reduction Mechanisms Using Computer Code. International Journal of Science and Qualitative Analysis. Vol. 2, No. 2, 2016, pp. 19-23. doi: 10.11648/j.ijsqa.20160202.12

Received: September 3, 2016; Accepted: October 20, 2016; Published: November 8, 2016

\begin{abstract}
In order to protect public health and safety from the inadvertent release of radioactive materials, during a reactor accident the defense-in-depth strategy must include; multiple layers of protection, such as prevention of accidents, mitigation features and emergency preparedness program that include measures such as sheltering and evacuation. In the present work RASCAL computer code is going to be used to estimate the offsite consequences of a nuclear sever accident using release pathway reduction mechanisms in order to obtain an appropriate release at a Pressurized Water Reactor (PWR) operating at its full power. The existing plant (systems, equipment) assuming that will be used for accident mitigation. Calculation of the total effective dose associated with this reduction is proposed. The data obtained showed that the spray system is the most effective mechanism to mitigate dose release during the accident.
\end{abstract}

Keywords: Sever Accident, Nuclear Emergency, Total Effective Dose, RASCAL Code

\section{Introduction}

Consideration of severe accidents at a nuclear power plants (NPP) is an essential component of the defense in depth approach used in nuclear safety. Severe accidents have a very low probability, but may have significant consequences resulting from nuclear fuel degradation. Severe accidents can be classified from the 4th level to the 7th level of INES (International Nuclear Events Scale).Severe accidents may involve very complex physical phenomena that take place sequentially during various stages of accident progression. Computer codes are essential tools for understanding how the reactor and its containment might respond under severe accident conditions. The codes are used as a tool to support engineering judgment, based on which specific measures to mitigate the effects of severe accidents are designed. Moreover they are also used to determine accident management strategies and for probabilistic safety assessment (PSA). Beyond design basis accidents: Accident conditions will be more severe than a design basis accident.
It may or may not involve core degradation [1]. The accident at the Fukushima Dai-ichi nuclear facility in Japan highlighted the need for safety improvements for nuclear power plants related to beyond-design-basis natural hazards and the resulting effects on plant systems and barriers from an extended loss of electrical power and access to heat removal systems [2]. The containment structures are designed to withstand the design basis accident-induced pressure and temperature and maintain a certain degree of leak tightness [3]. Ventilation containment can help in preventing or delay the loss of cooling, or facilitate the recovery of, important safety functions such as reactor core cooling, reactor coolant inventory control, containment cooling, and containment pressure control [2]. Containment Leakage in PWRs While radionuclides are held up in the containment atmosphere, they will be subject to be removed from the containment by water sprays as well as by natural processes that causes the deposition of radionuclides on the containment surfaces. Figure 1 illustrates $\mathrm{PWR}$ an containment. 


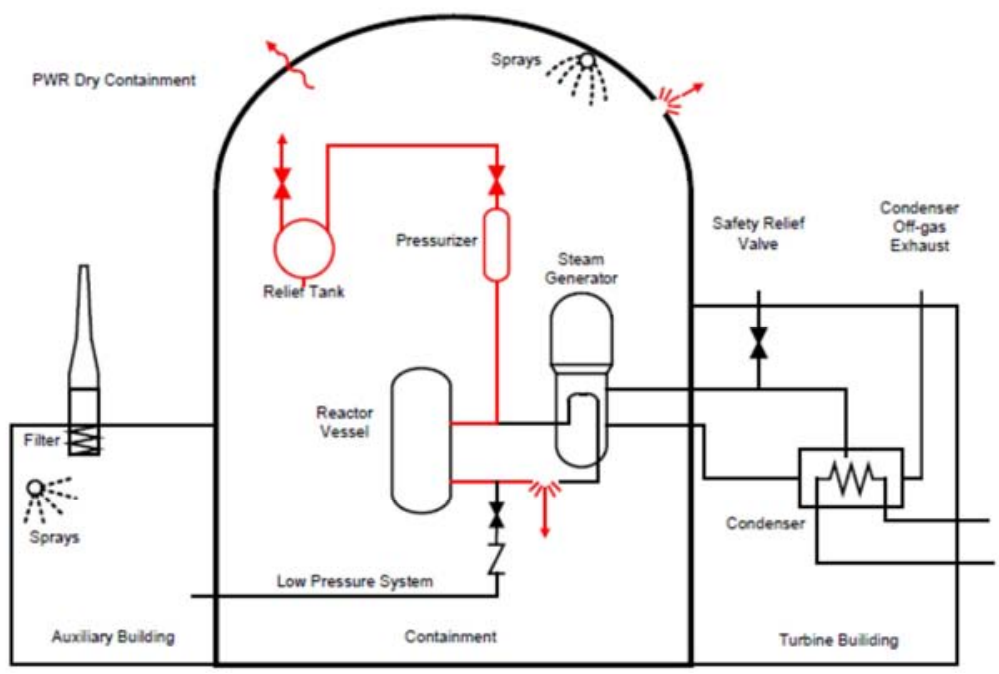

Figure 1. PWR Reactor containment.

\subsection{RASCAL Computer Code Description}

RASCAL code which stands for Radiological Assessment System for Consequence Analysis, is the software developed and used by the U. S. Nuclear Regulatory Commission (NRC), Emergency Operations Center in order to estimate the projected doses in case of radiological emergencies. Various reduction mechanisms are going to be modeled by RASCAL. The reduction of the source term by sprays is treated as an exponential function with time. There is an initial effectiveness that is going to be applied for the first 15 minutes that radionuclides are in the containment atmosphere and then reduced effectiveness acting after 15 minutes will be according to equation (1).

$$
R D F=e^{-\lambda T}
$$

Where $\mathrm{T}$ is the total amount of time (h) that the sprays have been operating and lambda $(\lambda)$ is $12 / \mathrm{h}$ for the first 15 minutes and $6 / \mathrm{h}$ after 15 minutes. For PWRs with ice condenser containments, additional reductions can be taken due to interaction of the containment air with the ice. If the fans are recirculating the containment air through the ice beds for at least an hour, the activity entering the containment is reduced by using a reduction factor RFi multiplier of 0.25 . If the fans are not operating the reduction factor RFi multiplier will be 0.5 . After the ice beds are exhausted, the reduction factor RFi multiplier equal 1. RASCAL model calculate the leak rate through a hole in the containment and containment pressure using equation (2).

$$
\operatorname{MFR}(K)=C\left(\frac{\pi D^{2}}{4}\right) \sqrt{2 \rho\left(P_{1}(K)-P_{2}\right) g}
$$

Where $\operatorname{MFR}(\mathrm{k})$ is the mass flow rate out of containment, during time step $\mathrm{k}$.

$\mathrm{C}=0.63$, an experimentally measured discharge coefficient that rarely varies outside the range of $0.59<\mathrm{C}<$ 0.65 and is dimensionless, $\mathrm{D}=$ hole diameter in inches, $\rho=$ density of containment atmosphere in pounds per cubic inch,
$\mathrm{P} 1(\mathrm{k})=$ pressure in containment during time step $\mathrm{k}$ in pounds per square inch, $\mathrm{P} 2=$ atmospheric pressure in pounds per square inch, $\mathrm{g}=$ acceleration of gravity in inches per second to convert between pounds and a mass unit [4]

\subsection{Basic Input Parameters}

The surrounding area of the postulated nuclear power plant with a radius of $80 \mathrm{~km}$ was subdivided into 13 concentric stripes and 16 sectors of $22.5^{\circ}$ (A,B,C,D,E,F,G,H,J,K,L,M,N,P,Q,R) with the plant located at the center of the concentric circles. The distances of the outer arcs of the concentric stripes from the center were $0.1,0.2,0.3$, $5,8,10,15,20,24.1,32.2,48.3,64.4$, and $80.5 \mathrm{~km}$, respectively. In numbering the sectors, the angles were calculated in clockwise sense with the north direction in the middle of the 1 st sector. The concentric stripes intersected with the sectors to form a geographical grid as shown in Figure. 2

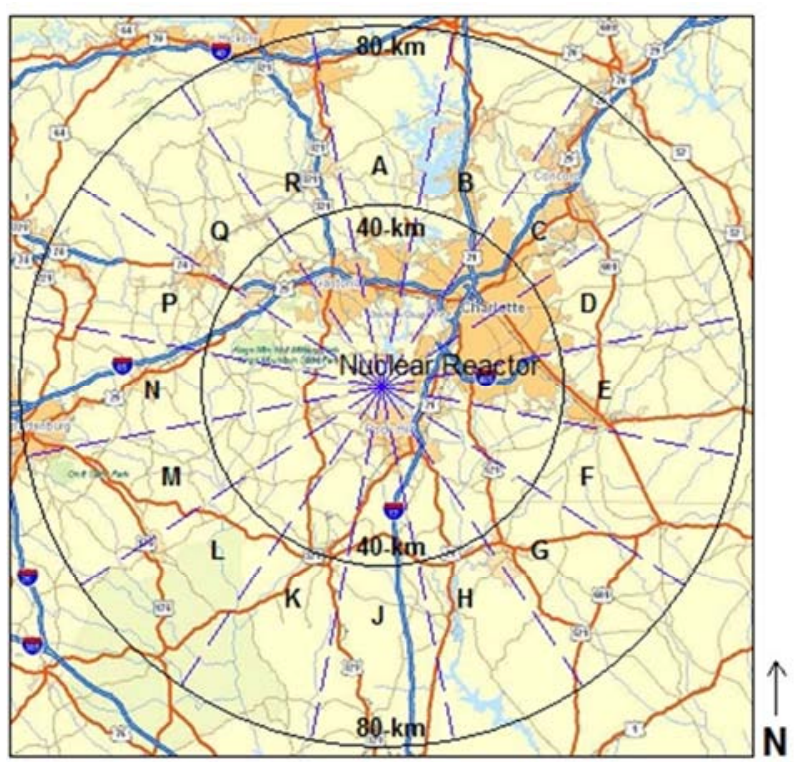

Figure 2. The postulated nuclear power reactor surrounding area. 
The weather data are measured on a multi-level tower and consist of wind speed and direction, air temperature, and atmospheric stability. The reporting and averaging interval may vary but is usually 15 minutes. Note that precipitation is not measured or reported. Normally you will enter the data measured at the lowest tower level (typically $10 \mathrm{~m}$ or $30 \mathrm{ft}$ ). You can use elevated measurements but will need to change the measurement height in the program. RASCAL adjusts winds to the release height so using surface data is not an issue. ERDS has some limitations with respect to weather data. It is assumed the opening will remain open for 3 hours and then be completely closed. In our case, use the predefined Standard Meteorology data set as follow in table (1).

Table 1. Standard Meteorology data.

\begin{tabular}{ll}
\hline wind direction (deg) & $\mathbf{2 7 0}$ \\
\hline wind speed and (mph) & 4 \\
atmospheric stability & D \\
precipitation & No prec. \\
\hline
\end{tabular}

\subsection{Scenarios Description}

A postulated Nuclear Plant, a PWR $1000 \mathrm{MW}$ with ice condenser containment had been operating at full power. The reactor scrammed at a certain time and the core was uncovered. There was a direct release path through the pressurizer relief tank. We assume that the release to the environment started as soon as the core was uncovered. We will first run this problem After the initial run, we will make changes to the release pathways to reduce the size of the release. There are six cases to calculate source term and doses.

Case 1: Non active reduction mechanisms operating, with a $10 \mathrm{~cm}$ diameter hole in the containment with containment at the maximum design pressure of $103 \mathrm{Kpa}$. It is assumed that the hole remain open for 3 hours (from 13:30 until 16:30) and then be completely closed.

Case 2: Reduce the containment pressure by a factor of 3 ; from $103 \mathrm{kpa}$ down to $34 \mathrm{kpa}$

Case 3: Reduce the hole size to $5 \mathrm{~cm}$ diameter with pressure at $34 \mathrm{kpa}$

Case 4: Assume that the ice bed is not exhausted

Case 5: Turn on the recirculation fans

Case 6: Turn on the sprays

\section{Results and Discussion}

The mechanism changes for all studying cases describes at table (2). In the early phase : Core heat-up due to decay of
Fission Products (FP), Core material oxidation (by steam), Liquefaction and melting of core materials and release and transport of Fission Products. A comparison between total effective doses equivalent (TEDE) at different distances away release point for all cases was illustrated in figure 3 . It is clear that there is highest (TEDE) in case 1, where all mechanism off and Ice bed exhausted. There is a slightly decrease in TEDE value for case2, due to the pressure decreasing by factor 3 so immediately evacuation for zone (PAZ 3-5Km). The operating organization of a facility taking migratory actions in a nuclear or radiological emergency such as discharge of radioactive material to the environment, provided that the appropriate off-site organizations are notified in advance [5]. Sheltering and iodine prophylaxis uses for urgent precaution zone (UPZ15-30) to protect public. It is obvious that the use of fans in case 5 decrease TEDE about 18times, whereas the use of sprays in case 6 is the most effective to decrease TEDE dose. The containment spray pump will take suction from the refueling water storage tank and pump the water into spray rings located in the upper part of the containment. The water droplets, being cooler than the steam, will remove heat from the steam, which will cause the steam to condense. This will cause a reduction in the pressure of the building and will also reduce the temperature of the containment atmosphere (similar to the operation of the pressurizer). Like the residual heat removal system, the containment spray system has the capability to take water from the containment sump if the refueling water storage tank goes empty [6]. Figure 4 illustrate a comparison between release behavior of case 1 and case 6 . In case 1 the plume exposure pathway EPZ has a radius of about $10 \mathrm{Km}$ from the reactor site. The actions for this EPZ can include sheltering, evacuating, and taking potassium iodide pills to protect people who inhale or ingest airborne radioactive iodine. The ingestion exposure pathway EPZ has a radius of about $50 \mathrm{Km}$ from the reactor site. The actions for this EPZ can include a ban of contaminated food and water to protect people from radioactive material in the food chain [7]. It is noted that the use of mechanism, case 6 reduce release pathway to more than seven hundred times where there is no dangerous dose exist (exceed than $50 \mathrm{mSv}$ ). Figure 5 and 6 shows the change of release rate with time of the $\mathrm{I}^{131}$ and ${ }^{137} \mathrm{Cs}$ case 1 and case 6 results respectively. It is clear that a reduction factor of about $10^{3}$ is observed for sprays in the first hour and a factor of 107 after six hours. Acceptance criteria for sever accidents for long term effects the ${ }^{137} \mathrm{Cs}$ release limit needs to be below the prescribed value (e.g.100 TBq) [8].

Table 2. Mechanism change in different cases.

\begin{tabular}{lllllll}
\hline Mechanism change & Case1 & Case2 & Case3 & Case4 & Case5 & Case6 \\
\hline Sprays & Off & Off & Off & Off & Off & On \\
Recirculation fans & Off & Off & Off & Off & On & On \\
Ice bed & Not found & Not found & Not found & found & found & found \\
Hole size (diameter) & $10 \mathrm{~cm}$ & $10 \mathrm{~cm}$ & $5 \mathrm{~cm}$ & $5 \mathrm{~cm}$ & $5 \mathrm{~cm}$ & $5 \mathrm{~cm}$ \\
Containment pressure & $103 \mathrm{kpa}$ & $34 \mathrm{Kpa}$ & $34 \mathrm{Kpa}$ & $34 \mathrm{Kpa}$ & $34 \mathrm{Kpa}$ & $34 \mathrm{Kpa}$ \\
\hline
\end{tabular}




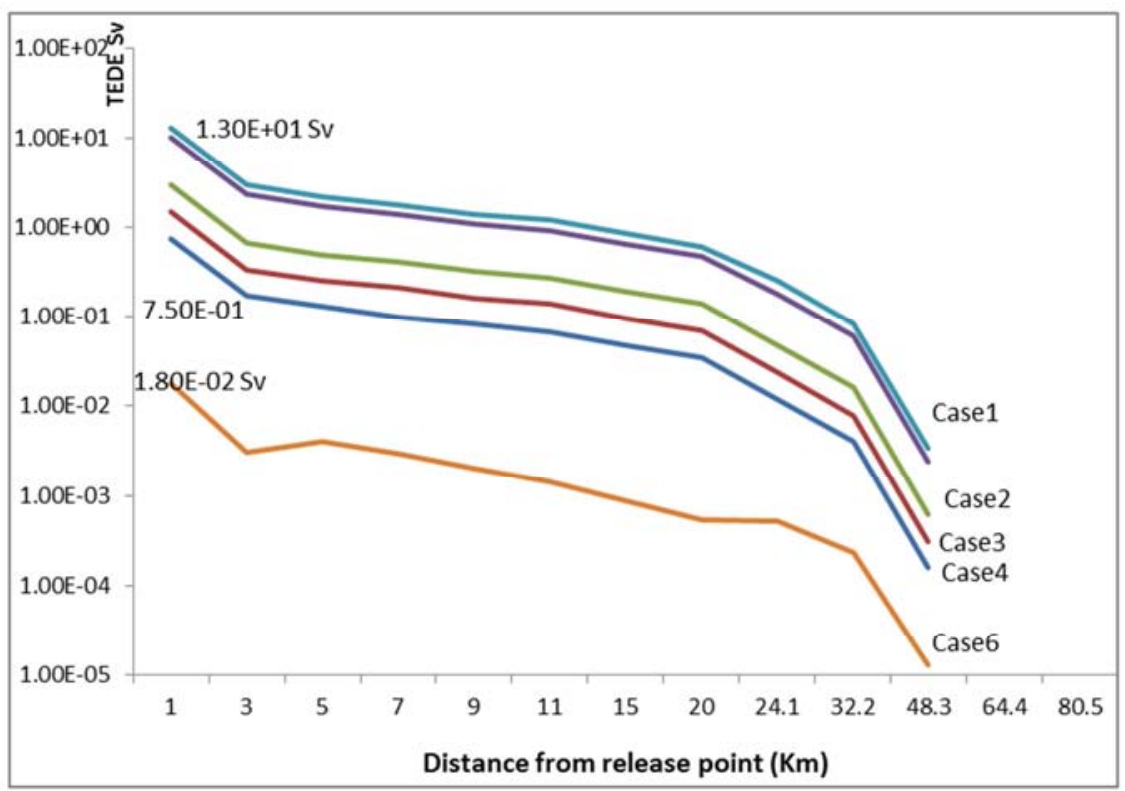

Figure 3. TEDE at different distances away from release point.

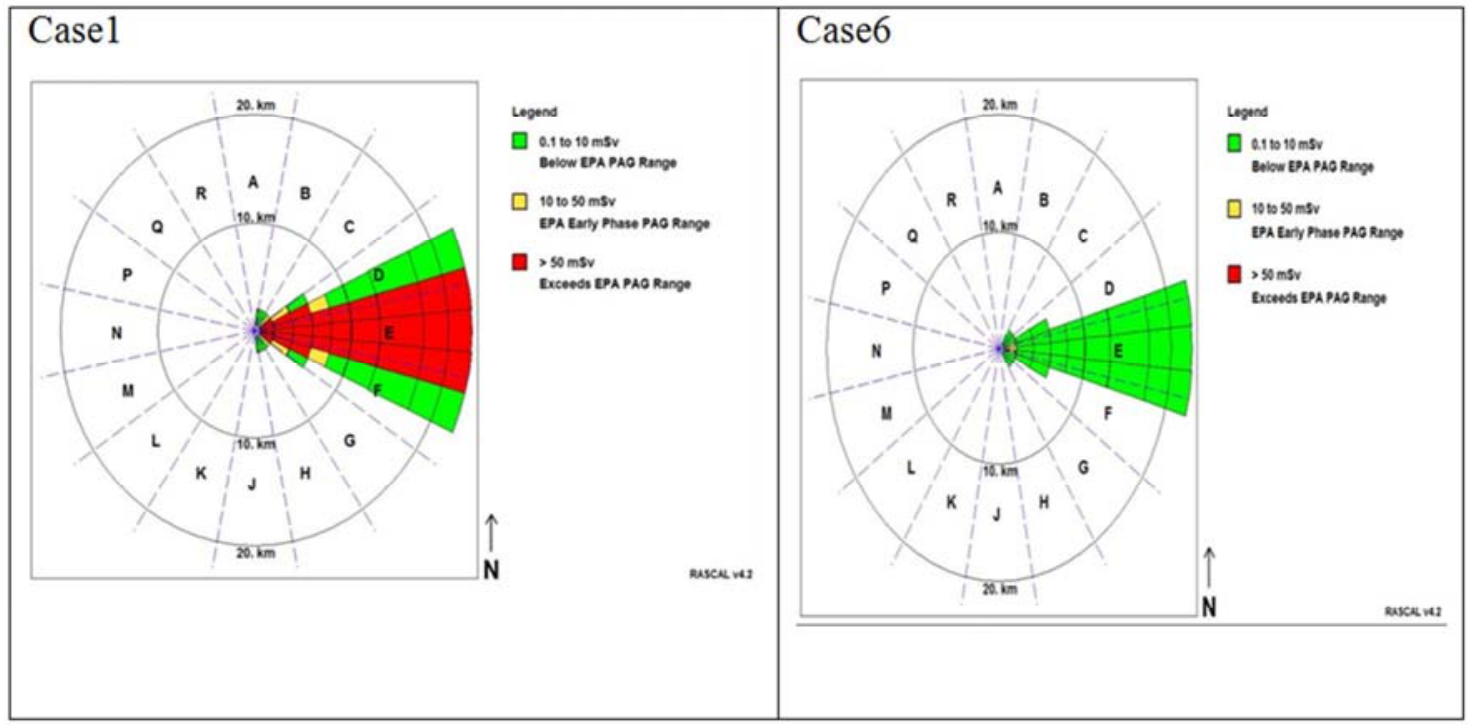

Figure 4. Release pathway in casel and case6.

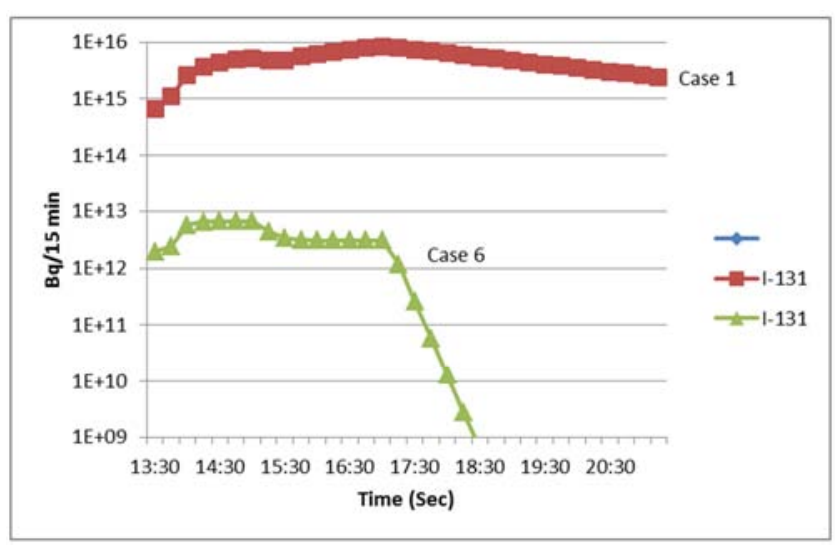

Figure 5. Rascal source term for I-131 radionuclide versus time.

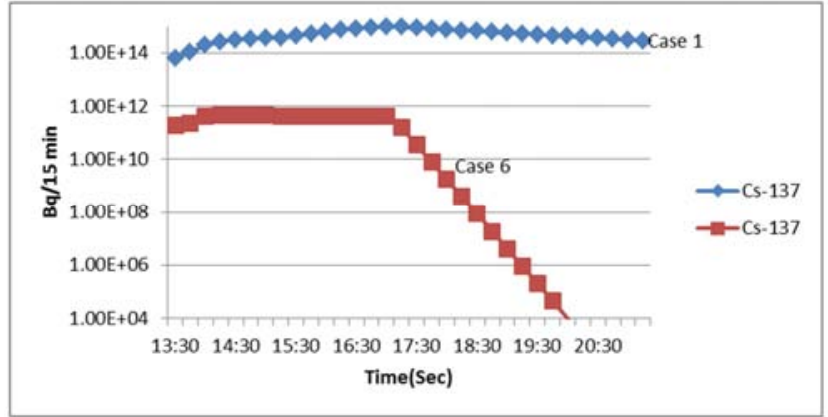

Figure 6. Rascal source term for Cs-137 radionuclide versus time.

\section{Conclusions}

Sprays can be very effective in reducing airborne fission 
production concentrations, where it is condense the steam inside the containment. If containment sprays are operating, they rapidly will reduce the concentrations of all radionuclides except for noble gases. If the sprays are not operating, the natural processes such as gravitational settling and plate-out on containment surfaces by turbulent impaction gradually will reduce airborne concentrations of particulates and reactive gases. Leak rate based on containment Pressure and hole size. The containment spray system provides cooling sprays of borated water from the upper regions of the containment in order to reduce containment pressure and temperature to value less than the design limit during a LOCA.

Release of radioactivity to the environment in the event of an accident in a reactor can be limited if the containment maintain structural integrity and the isolation system functions properly. Particularly as a result of a Loss of Coolant Accident (LOCA), the engineering safety feature (ESF) system functions to localize, control, mitigate and terminate such accident and hold exposure levels below the limits. Commonly shared principles for all types of NPPs and for all countries: "to prevent with high confidence accidents in nuclear plants; to ensure that, for all accidents taken into account in the design of the plant, even those of very low probability, radiological consequences, if any, would be minor; and to ensure that the likelihood of severe accidents with serious radiological consequences is the likelihood of severe accidents with serious radiological consequences is extremely small [9]. The preventive measures improving in order to further reduce the probability of core melt, and simultaneously incorporating, right from the design stage, measures for limiting the consequences of a severe accident. IAEA target values for core damage frequency (CDF) target values for core damage frequency (CDF)

- For existing plants: $10^{-4}$ per reactor-year

- For future plants: $10^{-5}$ per reactor-year

The general approach adopted by NEA member countries relies on all relevant aspects of the implementation of defense-in-depth (DiD) in the form of a series of design and procedure provisions to prevent and mitigate incidents and accidents that could lead to a large and early radioactive release. This concept is supported by emphasis on the inherent safety characteristics of the reactor, and insights from deterministic and probabilistic safety analyses to evaluate and optimize the overall plant design. During its October 2012 meeting, the NEA Steering Committee held a policy debate on nuclear safety defense-in depth. Participants in the debate recognized that the concept of defense-in-depth is valid, but that issues have been raised post-Fukushima regarding its implementation that need to be further reviewed and improved. They stressed that responsibility for safety lies with the operator, but that the regulator has an important role to play in ensuring that the barriers in place to protect the public and the environment remain effective [10].

\section{References}

[1] IAEA-TECDOC-1594 "Analysis of Severe Accidents in Pressurized Heavy Water Reactors" June 2008.

[2] NRC Commission's staff requirements memorandum (SRM) for SECY-11-0137, "Prioritization of Recommended Actions to Be Taken in Response to Fukushima Lessons Learned," dated December 15, 2011.

[3] A. K. Ghosh, V. V. Raj, and A. Kakodkara "A Scheme for Passive! Solation of the Containment of a Reactor" By NUCLEAR SAFETY, Vol. 34, No. 1, January-March 1993

[4] U.S. Nuclear Regulatory Commission "RASCAL 4: Description of Models and Methods" December 2012

[5] IAEA Safety Standards "Preparedness and Response for a Nuclear or Radiological Emergency" General Safety Requirements No. GSR Part 7, VIENNA, 2015

[6] USNRC Technical Training Center "Pressurized Water Reactor Systems" Reactor Concepts Manual, 2004

[7] U.S. Nuclear Regulatory Commission "Modeling potential reactor accident consequences" NUREG/BR-0359 January 2012.

[8] IAEA “ACCIDENT ANALYSIS FOR NUCLEAR POWER PLANTS WITH PRESSURIZED WATER REACTORS" SAFETY REPORTS SERIES No. 30, VIENNA, 2003.

[9] International Nuclear Safety Advisory Group (INSAG) INSAG-12 "Basic Safety Principles for Nuclear Power Plants 75-INSAG-3 Rev. 1" IAEA October 1999.

[10] Nuclear Energy Authority (NEA) "THE FUKUSHIMA DAIICHI NUCLEAR POWER PLANT ACCIDENT", NEA No. 7161, (C) OECD 2013. 